\title{
AC 2011-2343: NEW LAB PROJECT FOR NON-EE MAJORS PROVIDES HANDS-ON EXPERIENCE WITH ANALOG/DIGITAL, AND PROGRAMMABLE TEMPERATURE CONTROLLERS
}

Patrick Kane, Cypress Semiconductor Corp.

Patrick Kane Bio

Patrick Kane is the director of the Cypress University Alliance Program. The Cypress University Alliance Program is dedicated to partnering with academia and universities to ensure that professors and students have access to the latest Cypress PSoC technology for use in education and research. Patrick joined the Cypress team in July 2006. Prior to joining Cypress Patrick spent 13 years at Xilinx in a variety of roles including Applications Engineer, Aerospace and Defense, Automotive, Technical Training and managing the Xilinx University Program. He currently holds a BSEE and MBA degree.

Alexander Ganago, University of Michigan

Robert F. Giles, University of Michigan

Hongwei Liao, University of Michigan, Ann Arbor

(c)American Society for Engineering Education, 2011 


\title{
New lab project for non-EE majors provides hands-on experience with Analog/Digital, and Programmable Temperature Controllers
}

\begin{abstract}
We designed and implemented in Fall 2010 a new laboratory project in a large introductory course in Electrical Engineering (EE) for non-EE majors. This project provides hands-on experience with electronic devices that combine analog, digital, and programmable circuits, which engineering students can easily relate to projects in their field of major.

During 2 hours in the lab, students (in teams of two) work with two partly prebuilt temperature controllers (TC) that have the same functionality and use the same type of thermistor as the sensor, and the same actuators: 3 light-emitting diodes and a cooling fan (turning the fan on/off includes hysteresis). [\#1] The Analog/Digital TC is based on TC621 IC and two ICs with logic gates. [\#2] The Programmable TC is based on PSoC EVAL1 evaluation kit, which includes a Programmable System on the Chip by Cypress Semiconductor, donated through their University Alliance Program. All key concepts of this project are covered in lectures and may be transferable to other fields of engineering in which the students major.

Our learning objectives include: understanding the block diagrams and principles of operation; partial building of the circuits; verification of the functionality of both temperature controllers; varying the temperature set point by setting the potentiometer in controller \#1 and by programming of controller \#2.

In the Fall 2010 semester we offered this lab project to 209 engineering students in our introductory course for non-EE majors and collected feedback from 167 students in a survey with multiple-choice questions and in focus group discussions. 84\% students see this lab as interesting; $75-78 \%$ agree that theoretical concepts and in-lab procedures are clearly explained in the manual; $75 \%$ feel that the in-lab assignment helped them understand the principles of the system; $57 \%$ feel that they can apply the concepts and skills learned in this project to other courses; $54 \%$ students feel that these concepts and skills are valuable for their future careers.
\end{abstract}




\section{Introduction}

All engineering fields are getting intertwined with Electrical Engineering (EE) due to the unprecedented progress of analog/digital electronics and programmable devices. For example, many systems in your car, which used to be entirely mechanical (steering, braking, etc.), have become electronic and programmable! Therefore, knowledge of EE basics becomes necessary for all engineering specialties; non-EE Departments and programs require at least one EE course, which should prepare the students to function on multidisciplinary teams (ABET Criterion 3, d) ${ }^{1}$. However, undergraduate non-EE majors do not always see the relevance of EE to their field, thereby lacking interest in EE courses; their perception evolves when they get to the workplace or internship, when the opportunity for learning in required courses is already missed.

One of the best ways to engage the student interest in EE material is to provide hands-on experience with lab projects, which the students may see as relevant and valuable to their field of major: work with electronic devices that combine analog, digital, and programmable circuits typical of today's industrial equipment and consumer products. Creation of such projects involves a number of constraints:

(a) conceptual (students should be able to understand how the devices work);

(b) logistic (the project should be completed within a limited time in the lab);

(c) technical (the lab equipment should be adequate to test the functionality of the devices);

(d) financial (the devices should be of low cost), etc.

Institutions have various approaches to creating lab courses for non-EE majors; our literature search did not show any projects that involve computers and programmable devices along with circuit building, which could be completed within 2-3 hours of in-lab time. Several lab courses (not individual lab projects!) that set such goals are usually aimed at upper-level EE majors ${ }^{2,3,4,5}$ therefore they can hardly be used in an introductory course for non-EE majors where a large part of the limited lab time is spent on teaching the basics of electric circuits and electronics.

Here we report the design and implementation of a new laboratory project that addresses all of the issues listed above. We created a new Temperature Controller Lab and offered it in the Fall 2010 semester to 209 engineering students in our introductory course for non-EE majors. All key concepts of this project were covered in lectures, and many are transferable to other fields of engineering, in which the students major. Due to careful design of the assignment, all student teams completed the in-lab work within 2 hours as scheduled, which is among the key factors for student satisfaction with the lab. We collected feedback in several formats and found that many students see this lab as interesting, enjoyable, and valuable for their learning and their future careers.

Our investigation of the student feedback relates to studies on interdisciplinary learning ${ }^{6,7,8}$ and learning in groups or teams ${ }^{9,10}$. We plan to continue our research of the outcomes of this lab for student learning in their courses of major. 


\section{The student audience}

In the Fall 2010 semester, 209 engineering students were enrolled in our introductory EE course for non-EE majors. Their demographic information is obtained from the official class roster and presented in Figures 1 and 2.

As shown in Figure 1, 42.1\% major in Mechanical, 31.1\% in Aerospace, and 16.7\% in Nuclear Engineering; the remaining $10 \%$ belong to several other programs, including Engineering Physics, or have not declared their field of major.

Figure 2 shows that $66.0 \%$ of our students are juniors, $32.1 \%$ seniors, with very few sophomores and one graduate student.

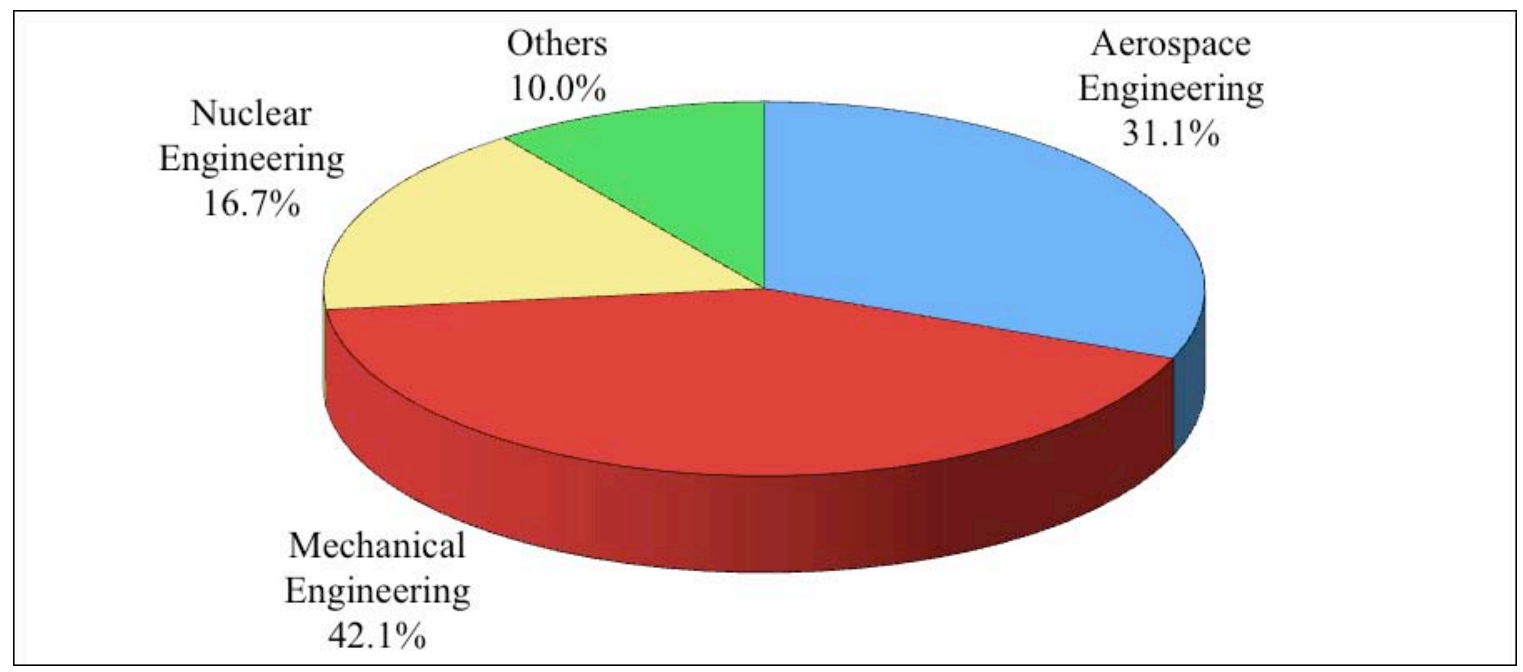

Figure 1. Students enrolled in our EE course for non-EE majors come from several programs, predominantly, Mechanical, Aerospace, and Nuclear Engineering.

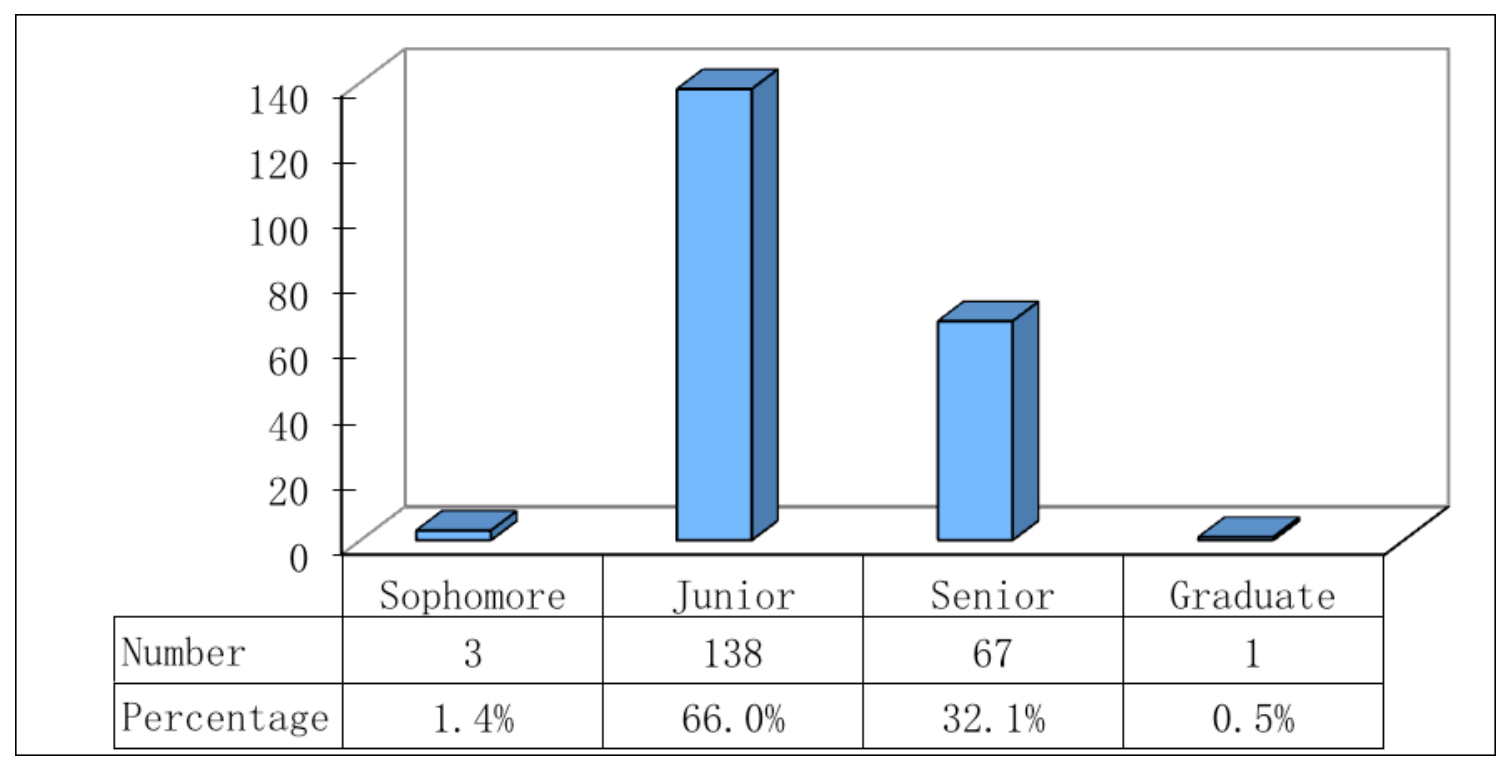


Figure 2. Two thirds of the 209 students enrolled in our course are juniors, about one third are seniors, with a very small number of sophomores, and one graduate student.

\section{The structure of the course}

Our 4-credit introductory EE course for non-EE majors is offered during a 14-week semester and includes the following components:

- lectures (3 hours per week)

- discussions (1 hour per week)

- laboratory work (2-hour session every two weeks; total, 6 lab projects per semester).

The lectures cover topics from the basic laws of electric circuits to transients, filters, analog and digital electronics, microprocessors and embedded systems. The 6 lab projects include: DC Lab, AC Lab, Transients Lab, Filter Lab, Op Amp Lab, and the new Temperature Controller Lab.

\section{The new Temperature Controller Lab}

In the new lab project, we provide hands-on experience and comparison of two temperature controllers, each of which has 3 Light-Emitting Diodes (LEDs) and a cooling fan as actuators:

(1) Analog/Digital (A/D) Temperature Controller based on TC621 temperature controller IC and two ICs with logic gates - TC4467 and TC4468, shown in Figure 3;

(2) Programmable Temperature Controller based on PSoC EVAL1 (Rev D) evaluation kit that includes a Programmable System on the Chip (PSoC) by Cypress Semiconductor, shown in Figure 4; (donated through their University Alliance Program).

Both controllers have the same functionality, which is shown in Figure 5. (Figures $3-5$ are taken from the lab manual for students). 


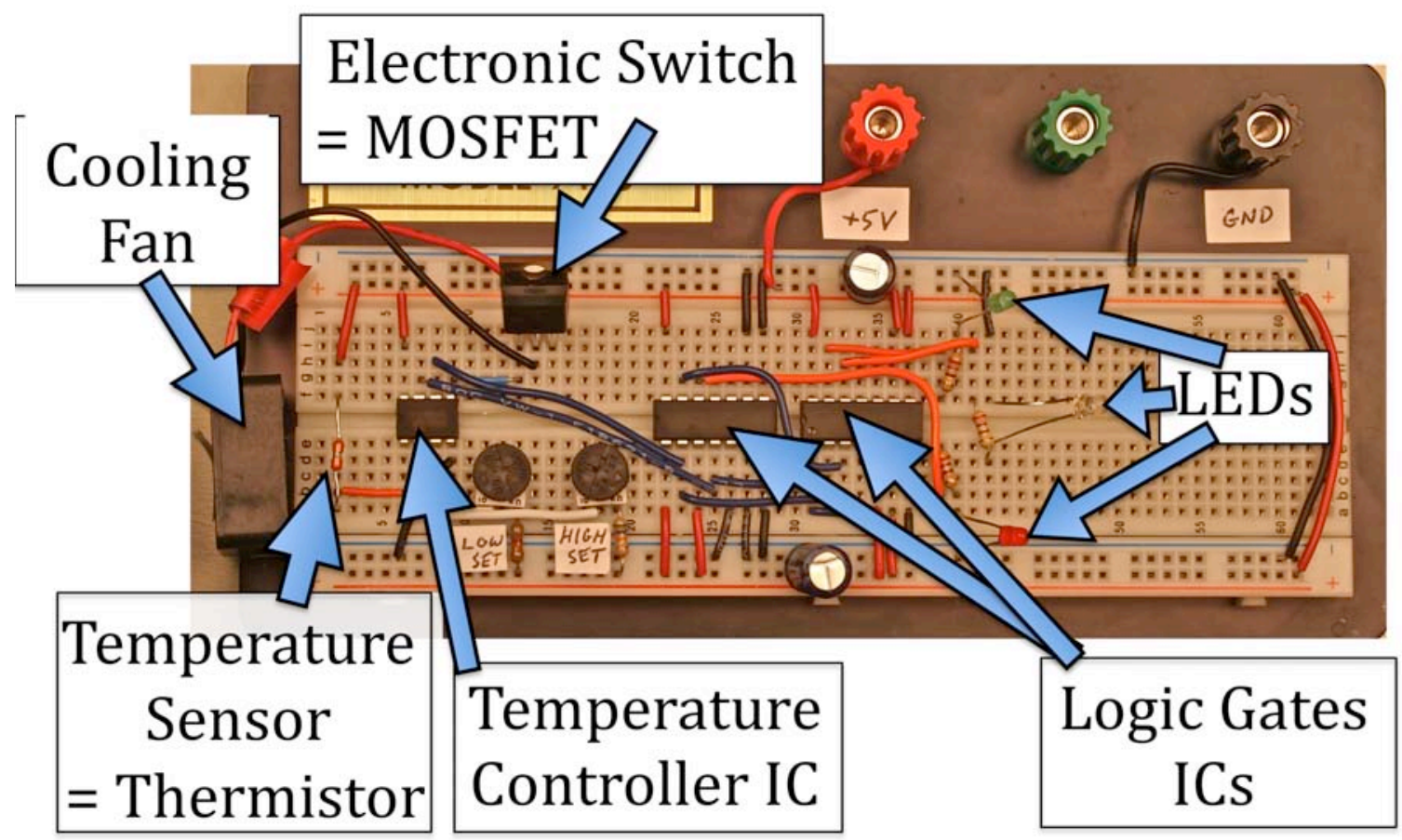

Figure 3. The circuit board with Analog/Digital Temperature Controller (from the lab manual for students).

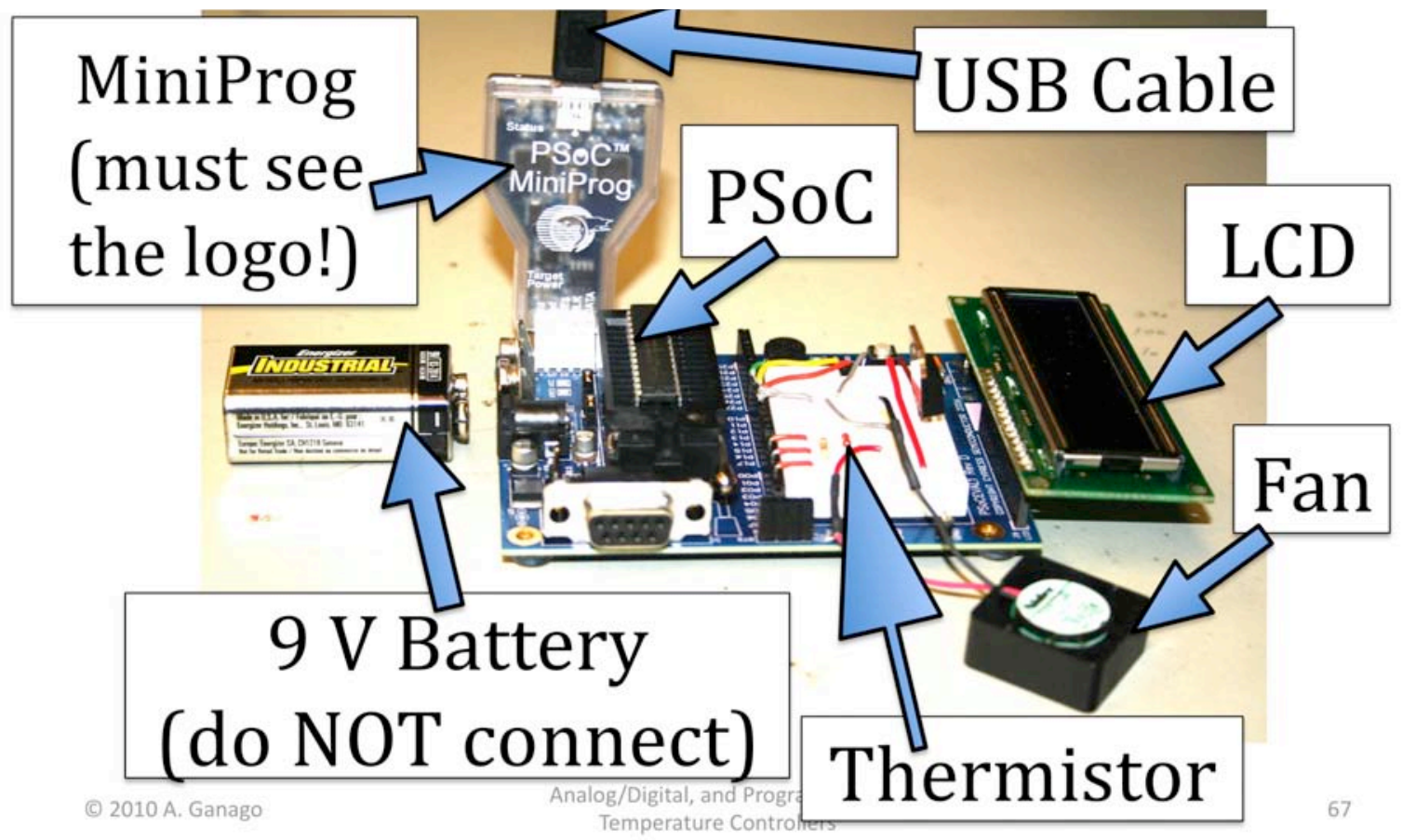

Figure 4. The Programmable Temperature Controller (from the lab manual for students). 


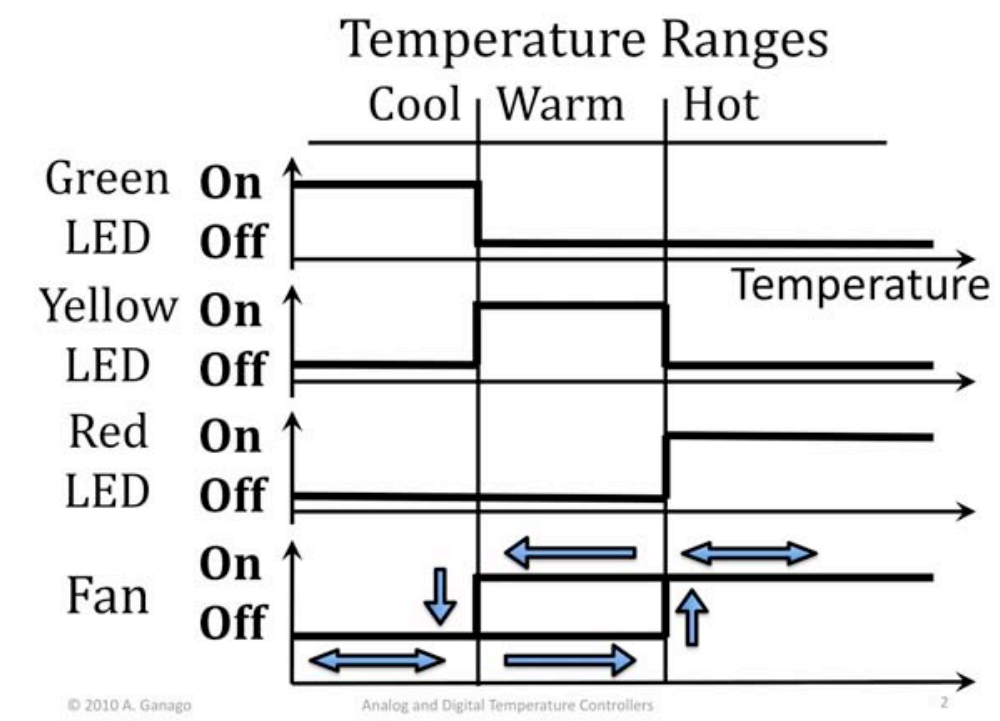

Figure 5. The functionality of Temperature Controllers: each controller determines the states of 3 LEDs and a cooling fan (from the lab manual for students).

Our Learning Objectives are:

LO1.Understand the block diagrams and principles of operation of the Analog/Digital and Programmable Temperature Controllers used in this Lab.

LO2. Complete the circuits partly built for you; verify the functionality of each Temperature Controller by observations and measurements.

LO3. For the Analog/Digital controller, demonstrate that the temperature set points are determined by the settings of potentiometers.

LO4. For the A/D controller, measure the voltages at several nodes, relate them to the logic states, and prove that they determine the states of the LEDs and fan.

LO5. Demonstrate that the Programmable Controller's functionality depends on the configuration of the input/output analog blocks and of the pins of the PSoC.

LO6. For the Programmable Temperature Controller, demonstrate that the $\mathrm{C}$ code determines the functionality; alter the $\mathrm{C}$ code to change this functionality.

The underlying concepts of the Lab were covered in lectures before students started to work on the lab: they include the block diagram of a control system with a sensor and actuators; hysteresis; Wheatstone bridge and comparator for monitoring/control; MOSFET as a switch; $\mathrm{A} / \mathrm{D}$ and $\mathrm{D} / \mathrm{A}$ conversion, etc. The lab procedures were also demonstrated in a lecture preview of the lab. 
The Pre-Lab assignment includes conceptual questions on the functionality of temperature controllers, with which students are familiar (as in the living room), along with problems where the functionality should be derived from the circuit diagram of a Wheatstone bridge with a comparator and MOSFET. Other problems include determination of the thermistor's resistance from the manufacturer's plot; finding of the fragments of $\mathrm{C}$ code that determine the status of each actuator, etc.

The 2-hour scheduled in-lab time is sufficient for students to work on both controllers: $\sim 1 / 2$ hour on the $\mathrm{AD}$ and $1 \frac{1}{2}$ hour or less on the Programmable Temperature Controller. At this stage of their learning in the course, students have already built several circuits with Op Amps (amplifiers, active filter, comparator) but, for the sake of saving valuable in-lab time, each temperature controller circuit is partly built for them so that the students only have to connect the actuators to the controller. This emphasizes the general strategy, or take-home message to the students: if you have a controller, you may attach any resistive sensor and any types of actuators to the same device in order to control other non-electrical parameters such as position, strain, light intensity, etc., applying the skills acquired in the lab to your future projects in other engineering fields.

Instructions for students on how to complete the circuit were provided step-by-step, as shown for example in Figure 6 for the AD controller (from the lab manual for the students).

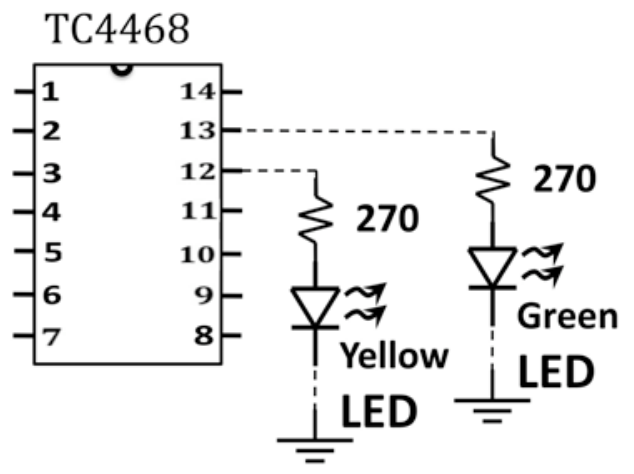

Insert two load resistors and two LEDs; connect to pins \#12 and \#13 of TC4468 and to the ground

Figure 6. Connections to be built for the Yellow and Green LEDs are shown with broken lines (from the lab manual for the students).

Figure 7 presents the complete circuit diagram of the $\mathrm{AD}$ temperature controller. 


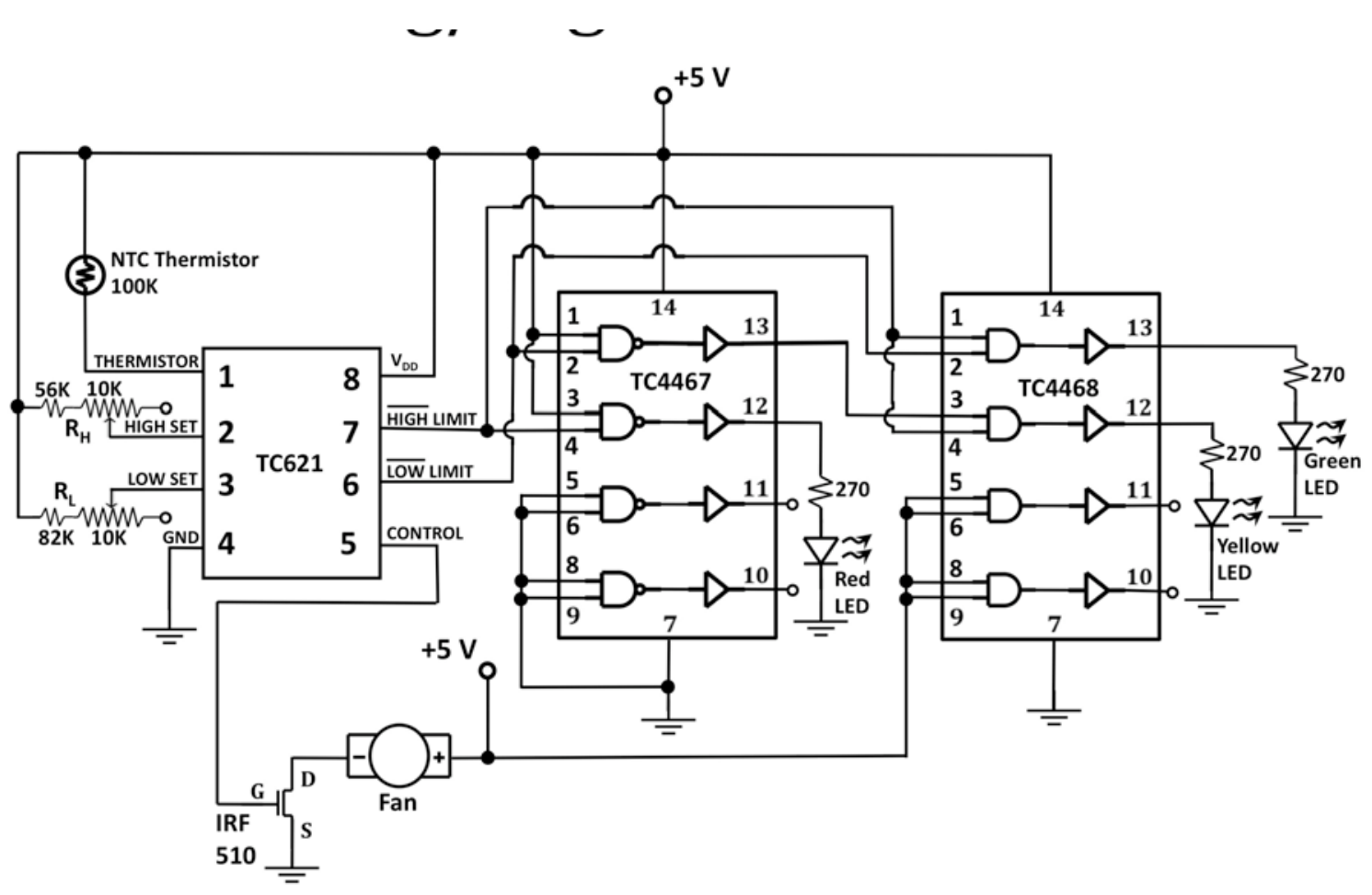

Figure 7. The complete circuit diagram of the $\mathrm{AD}$ temperature controller (from the lab manual). After they completely built the circuit of the AD temperature controller, students confirm its functionality (Figure 5) by bringing the tip of a hot soldering iron near the thermistor (not touching the thermistor), and measure the voltages at the specific pins of the IC chips to relate the voltage readings to the functionality.

For the programmable temperature controller, students also have to complete the circuit, as shown in Figure 8 (from the lab manual). 


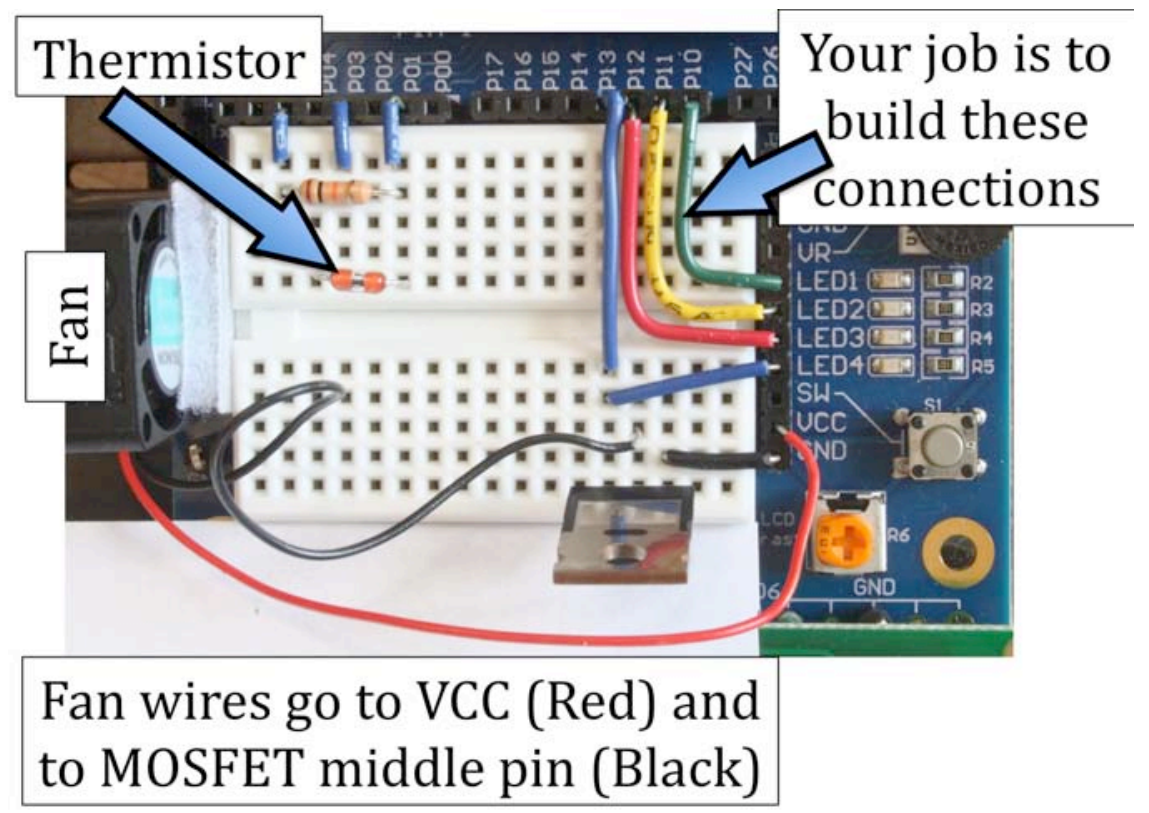

Figure 8. Circuit building instructions for the Programmable temperature controller (from the lab manual for students).

A significant part of in-lab work with the Programmable temperature controller is done on the PC (with which every student workstation is equipped). The input/output (I/O) pins of a PSoC device to ensure they provide enough power to drive the LEDs. Step-by-step instructions are provided, as shown for example in Figure 9.

\section{The Initial Pin Configuration}

\begin{tabular}{|c|c|}
\hline 田 Po[0] & Port_0_0, StdCPU, High Z Analog. [ A \\
\hline 田 Po[1] & V1_In. Analoglnput, High Z Analog. I \\
\hline 田 PO[2] & Port_0_2, StdCPU. High Z Analog. C \\
\hline 田 PO[3] & V2_Out. AnalogOutBuf_0, High Z An \\
\hline 田 PO[4] & Port_0_4. StdCPU, High Z Analog, C \\
\hline 田 Po[5] & Vo_Out. AnalogOutBuf_1. High Z An \\
\hline 田 $\mathrm{P}[6]$ & Port_0_6, StdCPU, High Z Analog. C. \\
\hline 田 PO[7] & AnalogColumn_InputMUX_2, Analog \\
\hline 田 $1[0]$ & LED1_green, StdCPU, High Z Analo! \\
\hline Đ P1[1] & LED2_yellow, StdCPU. High Z Analo \\
\hline 田 P1[2] & LED3_red, StdCPU, High Z Analog. \\
\hline 田 P1[3] & LED4_and_fan. StdCPU. High Z Anz \\
\hline 田 P1[4] & Port_1_4, StdCPU, High Z Analog, C \\
\hline 田 P1[5] & Port_1_5. StdCPU. High Z Analog. [ \\
\hline 田 P1[6] & Port_1_6, StdCPU. High Z Analog. [ \\
\hline 田 P1[7] & Port_1_7. StdCPU. High Z Analog. [ \\
\hline 田 P2[0] & LCDD4. StdCPU, Strong. Disableint \\
\hline 田 P2[1] & LCDD5, StdCPU. Strong. Disableint - \\
\hline
\end{tabular}

Figure 9. This screenshot shows the initial pin configuration, which students have to alter in order to ensure the required functionality (from the lab manual). 
After they set the desired configuration, students compile, or build the project (see an example of the instructions in Figure 10) and download it from the PC on the PSoC.

\section{Is Your Building Successful?}

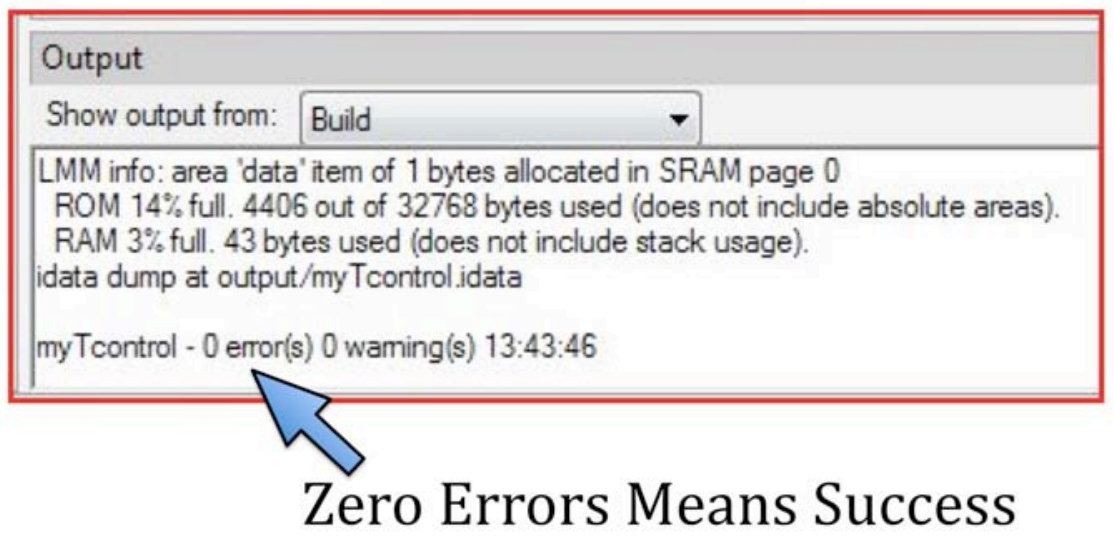

Figure 10. Fragment of the instructions for building the project (from the lab manual).

By the design, the initial building produces only partial functionality: the fan is not activated until another pin is reconfigured, and the updated project is built and downloaded on the PSoC: this is the way to show students the importance of every step in compilation and downloading of the project. Students need to verify the functionality of the entire controller with all 4 actuators involved.

Eventually, students are required to alter the $\mathrm{C}$ code for the Programmable controller, namely, to change the constant that determines the borderline between the Cool and the Warm temperature ranges. After this modification (followed with building and downloading), students check the functionality again, in order to observe the effect of the alteration of the $\mathrm{C}$ code. This exercise does not require any programming skills.

\section{Student feedback on the new Temperature Controller Lab}

We have designed and implemented a comprehensive survey of student learning in this lab. The survey consists of three parts:

(a) 15 statements about the lab are provided, and the students were asked to express their level of agreement on each of these statements, ranging from "strongly agree" to "strongly disagree", in the form of multiple-choice questions. The questions and standard "bubble forms" were offered to students right after they finished the in-lab work. Out of $\sim 209$ students in the course, 167 , or $79.9 \%$ anonymously participated in this part of our survey. 
(b) After the completion of their in-lab work (and completion of part (a) of the survey), students were invited to a conference room where a neutral surveyor conducted focus groups with open-ended questions and interactive discussion about the lab. About 50$60 \%$ of students who participated in the first part of the survey also participated in the second part.

(c) When students submitted their lab reports, they also filled in the feedback page, answering close-ended and open-ended questions about this Lab project. This part of the survey was not anonymous.

The results of our survey reveal a very positive attitude of students to the new Lab project. For example, $71.9 \%$ students agreed or strongly agreed with the statement "I found this lab project valuable for my learning": the statistics is shown in Figure 11.

Also, 74.9\% students agreed or strongly agreed with the statement "the in-lab assignment helped me understand the principles of the system" (Figure 12).

$82.6 \%$ students agreed or strongly agreed with the statement "In this lab, I used electronic devices to control non-electric parameters, and gained hands-on experience applying these principles to temperature control."

The lab has also helped students to see the value of their learning to the everyday life. $84.4 \%$ students agreed or strongly agreed with the statement "I found this lab project interesting." 


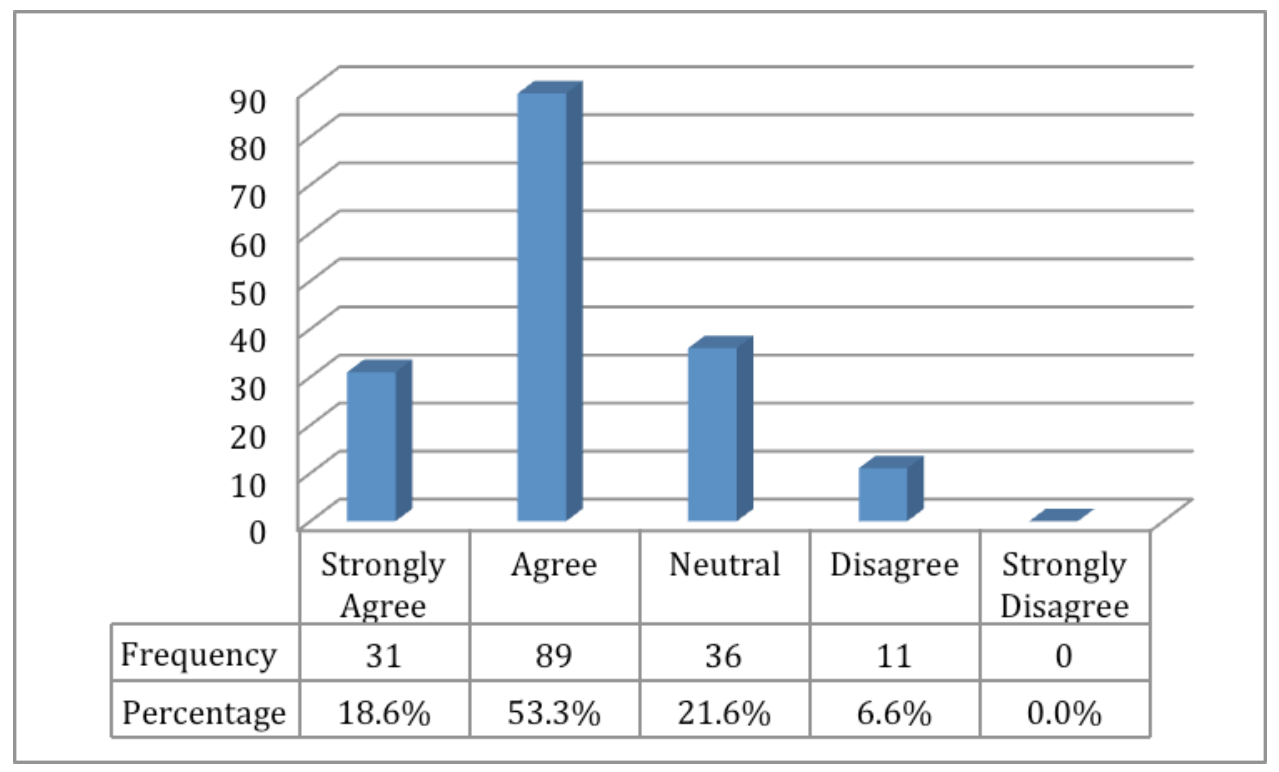

Figure 11. The students' responses to the statement "I found this lab project valuable for my learning."

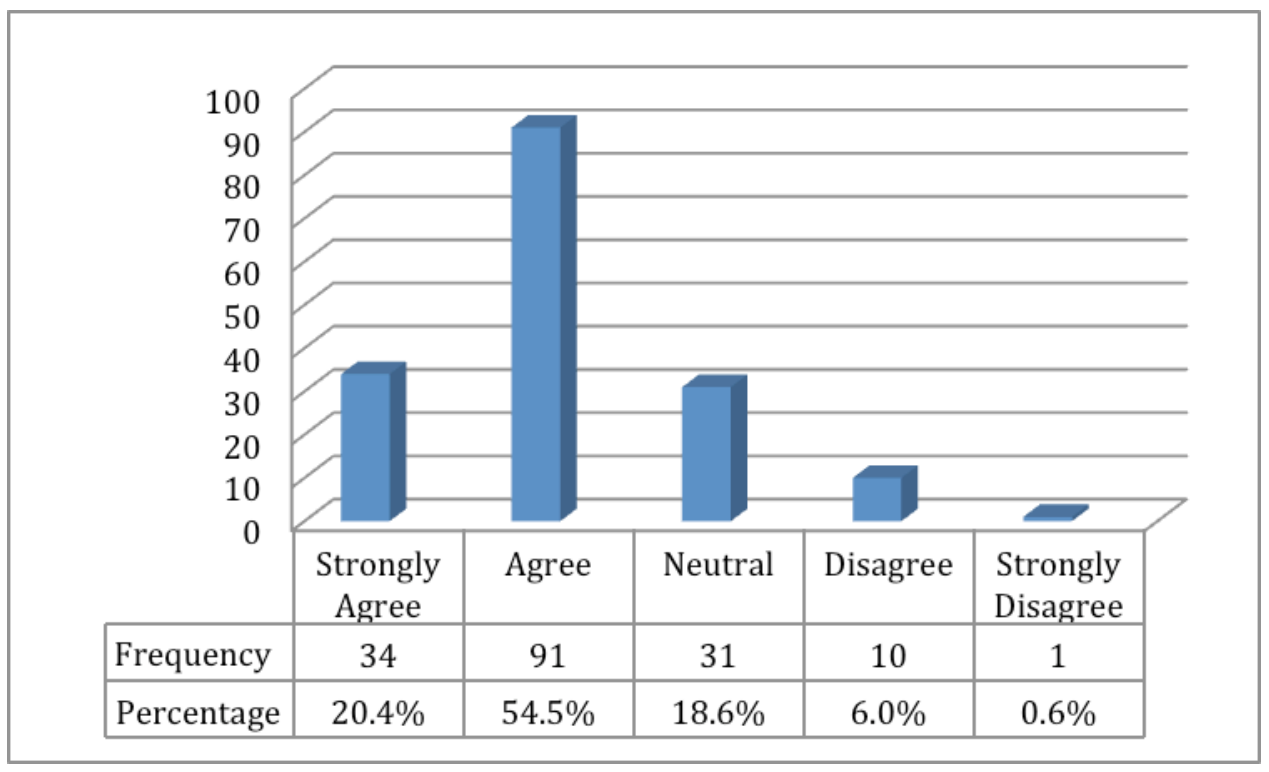

Figure 12. The students' responses to the statement "The in-lab assignment helped me understand the principles of the system." 
$53.9 \%$ students agreed or strongly agreed with the statement "I feel that the concepts and skills learned in this lab are valuable for my future career" (Figure 13). This outcome proves that the new Lab project is successful in engaging student interest and appreciation of the transferable skills they acquired in our EE course.

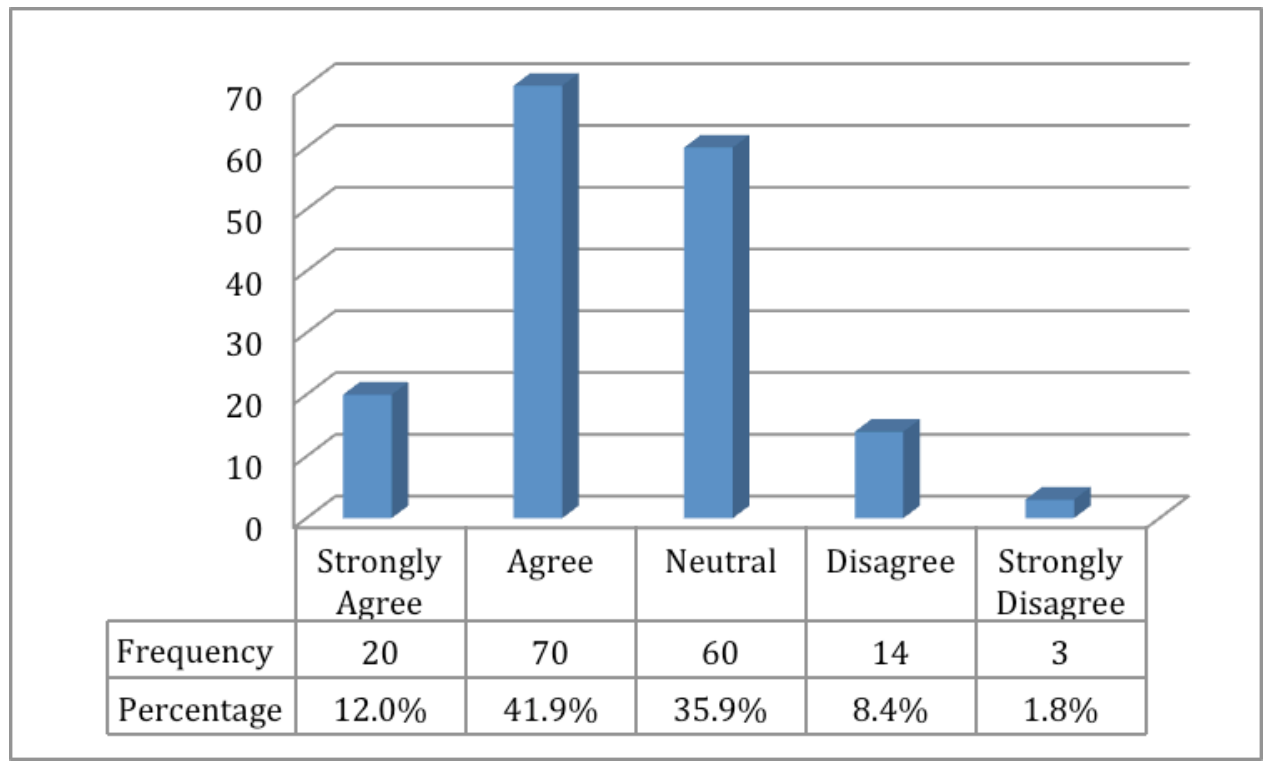

Figure 13. The students' responses to the statement "I feel that the concepts and skills learned in this lab are valuable for my future career."

The focus group discussion further reveals the learning outcomes of the students. From this lab project, students learned a variety of important technical concepts and components in EE. Students' responses include: "use of MOSFET", "hysteresis phenomenon in the circuit", "switching circuit", "programming of embedded systems", "logic controllers", "data acquisition (through sensors)", "feedback control", "integration of virtual program and physical system", "user interface design", etc.

The lab has also helped students to see the value of their learning to the everyday life. Many students in the focus groups expressed that "the system studied in this lab is very applicable to life." One student noted: "(I learned) how to manipulate circuits to achieve goals that are not related to electronics itself, like temperature." Another student pointed out: "the concept of feedback control (can have) many applications in real life."

Discussions in focus groups demonstrated students' ability to comprehend concepts and their relationships to other projects; students listed several courses in Mechanical, Nuclear, Aerospace and other fields of Engineering, for which their learning in this lab would be valuable. Nearly half of the students agreed or strongly agreed with the statement "I would like to learn more about EE beyond the scope of this lab and this course." The learning goal of this lab was reached. 


\section{Student opinions on how this lab project can be improved}

Due to the diversity of our student body, the opinions on possible improvement of this project vary and often contradict each other.

For example, the majority of students want to see more circuit building, while others suggest that all circuits should be completely prebuilt for them by the teaching staff. A significant number of students prefer to do more coding and less wiring. Several students wrote that they would need more time in the lab, while others complained that they did not have enough work to do within the scheduled time.

Also contradictory are the comments on Lab manual: some students want to see less detailed and repetitious instructions, while others write that they need more instructions.

\section{Learning beyond the Lab and the Course}

The system studied in this lab project involves many aspects of EE and general engineering techniques. Students from various majors found its close connection to their future major studies and careers. A mechanical engineering student said: "(the learning in this lab) matches up perfectly with our course on systems and dynamics." Another mechanical engineering student mentioned that "(the lab motivates his/her) interest in mechtronics", which is an emerging interdisciplinary research area integrating $\mathrm{EE}$ and mechanical engineering. A nuclear engineering student said: "(this lab is) related to Nuclear Instrumentation Lab" in their major. An aerospace engineering student noted that he "observed the use of programmable controllers during internship at NASA", and appreciated the connection of this lab to his/her future career. Another student also saw "the connection (of this lab) to the past internship experience with HVAC systems." Many students felt that the lab project has helped improve their ability to work on a multi-disciplinary team and communicate with people from other major backgrounds, which addresses the ABET outcomes $(\mathrm{d})$ and $(\mathrm{g})$ for engineering programs. One student, who has been involved in a multi-disciplinary project in his/her home department, said that the lab made him more confident to "work on large, comprehensive project, and communicate with electrical engineers on the team."

Many students expressed their interests in having further in-depth learning of the lab. The students' responses on their learning interests beyond the scope of this lab and course include: "the feedback control algorithms" [related to Control and Systems], "resolution of (sampled) data and the effect of over-sampling/under-sampling" [related to Signal Processing], "more about the analog circuit, (want to) build from scratch", "investigate the circuit more thoroughly", "more about MOSFET" [related to Microelectronics and Circuit Design], "programmable controller" and "program code" [related to Embedded Systems and Programming].

The overall opinion is probably expressed by one student who wrote along with his lab report: "One of the best labs and I'll be able to apply it to projects in my career."

\section{Conclusions}


Besides learning specific theoretical concepts and hands-on lab skills, and relating theory to their lab procedures and data, students develop interest in the course material outside their field of major. Their responses to open-ended questions in focus groups involve applications of the new knowledge to other fields and synthesis, or bringing together parts of knowledge to form a new whole and build relationships for new situations, which belong to levels 3 and 5 of the Bloom's taxonomy for the cognitive domain.

Students' learning in this lab also fosters the development of their multidisciplinary and communication skills - addressing Outcomes $(\mathrm{d})$ and $(\mathrm{g})$ of the ABET Criteria for Engineering Programs, which are very important objectives to achieve in a technical course such as an introduction to EE for non-EE majors.

Therefore we believe that our findings have value outside the scope of this particular course and institution.

\section{Bibliography}

1. ABET (2010-2011), Criteria for Accrediting Engineering Programs, Accreditation Board for Engineering and Technology (ABET). URL: http://www.abet.org/Linked\%20Documents-

UPDATE/Criteria\%20and\%20PP/E001\%2010-11\%20EAC\%20Criteria\%2011-03-09.pdf. Downloaded on March 11, 2011.

2. http://electricalprojectbd.blogspot.com/2010/06/engineering-ebook-practical-interfacing.html

3. http://www.nd.edu/ eeuglabs/ee224/lab-manual.pdf

4. Dave van Ess. Lab Manual for Introduction to Mixed-Signal Embedded System Design (PSoC Book). Cypress book. http://www.cypress.com/?rID=3300

5. A. Doboli and E. Currie. Introduction to Mixed-Signal Embedded Design. Springer, 2010. ISBN: 9781441974457

6. M. E. Gorman, L. G. Richards, W. T. Scherer, and J. K. Kagiwada (1995), Teaching invention and design: Multi-disciplinary learning modules, Journal of Engineering Education, Volume: 84, Issue: 2, pp.175-185

7. R. King, T. Parker, T. Grover, J. Gosink, and N. Middleton (1999), A multidisciplinary engineering laboratory course, Journal of Engineering Education, 88(3), pp.311-316

8. D.L. Maskell and P.J. Grabau (1998), A multidisciplinary cooperative problem-based learning approach to embedded systems design, IEEE Transactions on Education, 41(2), pp.101-103

9. T.A. Fredrick (2008), Facilitating better teamwork: Analyzing the challenges and strategies of classroombased collaboration. Business Communication Quarterly, 71, pp. 439-455

10. R. S. Hansen (2006), Benefits and problems with student teams: Suggestions for improving team projects. Journal of Education for Business, 82(1), pp. 11-19 